\title{
Active Vibration Control of Passenger Seat in Quarter Car Model using Supertwisting Controller
}

\author{
Devdutt Singh \\ Associate Professor, Manav Rachna International University, Faridabad, India \\ devdutt.ymca@gmail.com
}

\begin{abstract}
The objective of present study is vibartion control of passenger seat in active quarter car model having three degrees of freedom. Passenger ride comfort issues are considered under random road excitation using simulation work in time and frequency domain. The designed supertwisting controller is applied in main suspension of active quarter car model. The proposed controller showed effectiveness in vibration suppression of passenger seat acceleration and displacement responses as compared to passive one. Simulation work in graphical and mathematical results showed the superior performance of the designed supertwisting sliding mode controller.
\end{abstract}

Keywords: Supertwisting Controller, Active suspension system, Quarter car model, Passenger ride comfort

\section{Introduction}

Vehicle suspension system plays a crucial role in reducing the passenger seat as well as sprung mass vibrations, providing comfortable and safe ride and controlled suspension deflection to minimize the road induced vibrations. Theoretical and experimental research work in last few decades by academicians and by automotive industries have lead to the development of semi-active and active suspension systems [1-4]. Active and semi-active suspensions form closed loop systems which are electronically controlled and can enhance the ride comfort and road holding ability of the running vehicles. The damping characteristics in such suspension systems can be varied as per intensity of vibrations generated by uneven road surfaces. But, active suspension systems can deliver significantly higher level of desired performance in terms of ride comfort and safety of travelling passengers compared to conventional passive and semi-active suspension systems [5-6].

Active suspension systems provide high control performance related to passenger ride comfort and safety in a wide frequency range. Assembly of active suspension system contains sensors, actuators and controllers for achieving improved performance in vibration isolation. Sensors are responsible to measure the displacement and acceleration of various suspension parts such as passenger seat, sprung mass and suspension movement while controllable actuators supply necessary damping force in vehicle suspension system. In past, design, selection and application of various control approaches have been considered by various researchers in active suspension system, which include PID control [7], self-tuning fuzzy logic control [8], $\mathrm{H}_{\infty}$ control [9], sliding mode control [10], linear quadratic regulator control [11], linear quadratic gaussian control [12], fuzzy sliding mode control [13-14], linear parameter-varying control [15], neural network control [16], adaptive neuro fuzzy control [17-18] and Hybrid Fuzzy PID control [19-20], etc.

Received (June 1, 2017), Review Result (September 11, 2017), Accepted (October 20, 2017) 
In present study, super twisting sliding model controller is designed and used in the primary suspension system of active quarter car model with three degrees of freedom. Designed controller is tested using simulation work under random road excitations. Simulation results of controlled active suspension system are compared with passive one in terms of passenger seat as well as sprung mass acceleration and displacement response as well as main and passenger seat suspension response in time and frequency domain respectively.

\section{Active Quarter Car Model}

The active quarter car model having three degrees of freedom with controlled primary suspension system is shown in Figure1. It is used to study the passenger seat vibrations, sprung mass vibrations, suspension response to road input and control effort required for vibration control. The mass parameters of this quarter car model are passenger seat mass, $m_{p}$; sprung mass, $m_{s}$ and unsprung mass, $m_{u s}$ respectively. The damping and stiffness parameters for main suspension are $c_{2}$ and $k_{2}$ while for the passenger seat suspension, the damping and stiffness parameters are represented by $c_{1}$ and $k_{1}$ respectively. The tyre stiffness is represented by $k_{t}$. The damping force supplied by actuator in main suspension system is denoted by $F_{a}$. The displacement of passenger seat, sprung mass, unsprung mass and road profile are $z_{p}, z_{s}, z_{u s}$ and $z_{r}$ respectively while $\bar{d}$ indicates bounded external disturbance.

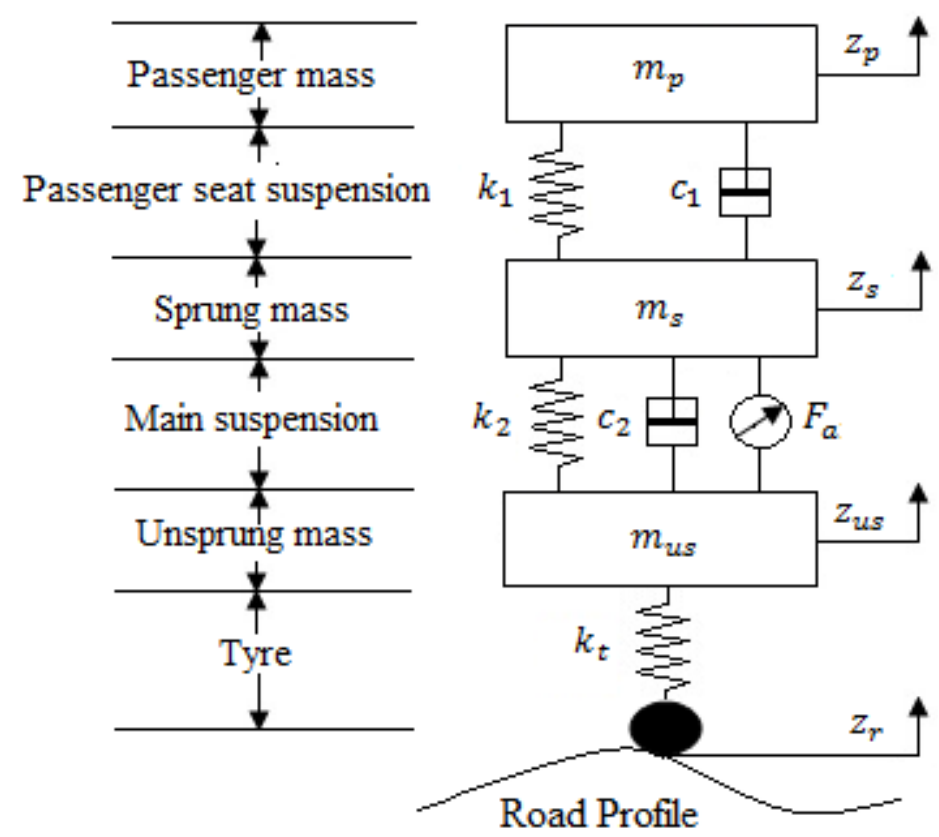

Figure 1. Active Quarter Car Suspension System

The mathematical equations of active quarter car model with three-degrees-of-freedom taking passenger seat dynamics can be derived using Lagrange's equations as follows:

$m_{p} \ddot{z}_{p}+c_{1}\left(\dot{z}_{p}-\dot{z}_{s}\right)+k_{1}\left(z_{p}-z_{s}\right)=0$

$m_{s} \ddot{z}_{s}-c_{1}\left(\dot{z}_{p}-\dot{z}_{s}\right)-k_{1}\left(z_{p}-z_{s}\right)+c_{2}\left(\dot{z}_{s}-\dot{z}_{u s}\right)+k_{2}\left(z_{s}-z_{u s}\right)$

$+F_{a}+\bar{d}=0$

$m_{u s} \ddot{z}_{u s}-c_{2}\left(\dot{z}_{s}-\dot{z}_{u s}\right)-k_{2}\left(z_{s}-z_{u s}\right)+k_{t}\left(z_{u s}-z_{r}\right)-F_{a}-\bar{d}=0$ 


\section{Super Twisting Sliding Mode Controller Design}

In this section, a Super Twisting Sliding Mode Controller (STSMC) based nonlinear observer is designed. STSMC controller is a special case of higher order sliding mode control which preserves the desirable properties, particularly invariance and order reduction as well as achieve better accuracy and guarantee finite-time stabilization of systems having relative degree of two.

Super twisting Sliding Mode Controller is a second order Sliding Mode Control algorithm which is unique and continuous, ensuring all the main properties of first order Sliding Mode control for the systems with Lipschitz matched uncertainties with bounded gradients and eliminates the chattering phenomenon. Super-twisting algorithm does not require the knowledge of the values of the derivatives and the knowledge of the perturbation. Super-twisting Sliding mode controllers are inherently stable.

In present section, a second order STSMC controller is designed. The aim of proposed STSMC controller is to reduce the road induced vibration response in active quarter car model. For the design of the STSMC controller, the dynamics of sprung mass under control is taken into account. The equation of motion of sprung mass response is written in the following state space model as:

$\dot{x}_{3}(t)=x_{4}(t)$

$\dot{x}_{4}(t)=-\frac{1}{m_{s}}\left[c_{2}\left(x_{4}(t)-x_{6}(t)\right)+k_{2}\left(x_{3}(t)-x_{5}(t)\right)\right]+\frac{1}{m_{s}} \bar{u}+\bar{d}$

where,

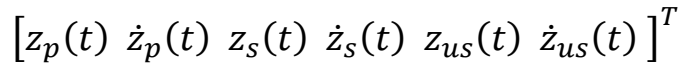

$\left[\begin{array}{llllll}x_{1}(t) & x_{2}(t) & x_{3}(t) & x_{4}(t) & x_{5}(t) & x_{6}(t)\end{array}\right]^{T}=$

Equation (5) can be written in the following form:

$\dot{x}_{4}(t)=f\left(x_{3}, x_{4}\right)+g\left(x_{3}, x_{4}\right) \bar{u}+\bar{d}$

where $x_{3}$ and $x_{4}$ are the states of the system, $\bar{u}$ is the supplied control input signal and $\bar{d}$ is the unknown bounded external disturbance $(\bar{d} \leq \Delta, \Delta>0)$.

\subsection{Selection of Sliding Surface}

The target of the designed controller is to supply the control input $u(t)$ to force the error signal to reach on the designed sliding surface, $s(t)$ and to make the system remain unaffected against external disturbances and changes in parameters. The selected sliding surface can be represented as:

$s(t)=\left(\frac{d}{d t}+\lambda\right)^{n-1} e(t)$

Since, the considered quarter car model is a second order system, thus by taking the magnitude of $=2$, the sliding surface can be written as:

$s(t)=\lambda e(t)+\dot{e}(t)$

where $\lambda$ is a positive constant and represents the slope of sliding surface.

The sprung mass displacement error, $e(t)$ and the time derivative of the sprung mass displacement error, $\dot{e}(t)$ can be represented as:

$e(t)=x_{3 d}(t)-x_{3}(t)$

$\dot{e}(t)=\dot{x}_{3 d}(t)-\dot{x}_{3}(t)$

where $x_{3 d}(t)$ is the desired displacement and $x_{3}(t)$ is the actual displacement of the sprung mass.

Taking the time derivate of the sliding surface from equation (8), we get:

$\dot{s}(t)=\lambda \dot{e}(t)+\ddot{e}(t)$

Putting the value of $\ddot{e}(t)$ in equation (11), we get:

$\dot{s}(t)=\lambda \dot{e}(t)+\dot{x}_{4 d}(t)-\dot{x}_{4}(t)$

$=\lambda \dot{e}(t)+\dot{x}_{4 d}(t)-f\left(x_{3}(t), x_{4}(t)\right)-g\left(x_{3}(t), x_{4}(t)\right) \bar{u}(t)-\bar{d}(t)$

Defining the following variables as:

$\Phi\left(x_{3}(t), x_{4}(t)\right)=\lambda \dot{e}(t)+\dot{x}_{4 d}(t)-f\left(x_{3}(t), x_{4}(t)\right)$ 


$$
\begin{aligned}
& u(t)=-g\left(x_{3}(t), x_{4}(t)\right) \bar{u}(t) \\
& d(t)=-\bar{d}(t)
\end{aligned}
$$

Finally, the time derivative of the sliding surface can be written as:

$$
\dot{s}(t)=\varnothing\left(x_{3}(t), x_{4}(t)\right)+u(t)+d(t)
$$

\subsection{Total Control Signal}

The total control signal, $u_{t}$ of STSMC controller consists of two parts, a discontinuous part, $u_{d c}$ and a continuous part or equivalent control, $u_{e q}$. The discontinuous part is responsible for driving the system states on to the sliding surface while the equivalent part is responsible for keeping the motion of the system on the sliding surface when it is on the sliding surface to force the error values to move towards the origin. The total control signal can be represented as:

$u_{t}=u_{e q}+u_{d c}$

Assuming that the perturbation and disturbance term $d(t)$ is globally bounded by:

$|d(t)| \leq \delta|s(t)|^{1 / 2}$

for some costant $\delta \geq 0$.

For the limit case, $\dot{s}(t)=0$ and nominal system, $d(t)=0$, the equivalent control can be defined as follows:

$u_{e q}=\varnothing\left(x_{3}(t), x_{4}(t)\right)$

The supplied control force for the discontinuous part by super twisting sliding mode controller for the chattering and perturbation elimination is presented as [21]:

$u_{d c}=-k_{1}|s(t)|^{\frac{1}{2}} \operatorname{sign}(s(t))+v(t)$

$\dot{v}(t)=-k_{2} \operatorname{sign}(s(t))$

where, $k_{1}$ and $k_{2}$ are positive constants.

Now, using the mathematical equation for the sprung mass, the control signal of the proposed STSMC controller in the main suspension of active quarter car model can be obtained as:

$\bar{u}(t)=-m_{s} u(t)$

Taking equation (16) into account, the mathematical equations of the sprung mass, the equivalent control, $u_{e q}$ can be designed while the discontinuous control, $u_{d c}$ can be represented as follows:

$u_{e q}=-\left[\lambda \dot{e}(t)+\dot{x}_{4 d}(t)+\frac{c_{2}}{m_{s}}\left(x_{4}(t)-x_{6}(t)\right)+\frac{k_{2}}{m_{s}}\left(x_{3}(t)-x_{5}(t)\right)\right]$
$u_{d c}=-k_{1}|s(t)|^{\frac{1}{2}} \operatorname{sign}(s(t))+v(t)$
$\dot{v}(t)=-k_{2} \operatorname{sign}(s(t))$

Finally, the total control signal is given as:

$$
\begin{aligned}
u_{t}= & u_{e q}+u_{d c} \\
= & -\left[\lambda \dot{e}(t)+\dot{x}_{4 d}(t)+\frac{b_{s}}{m_{s}}\left(x_{4}(t)-x_{6}(t)\right)+\frac{k_{s}}{m_{s}}\left(x_{3}(t)-x_{5}(t)\right)\right] \\
& -k_{1}|s(t)|^{\frac{1}{2}} \operatorname{sign}(s(t))+v(t)
\end{aligned}
$$

\subsection{Lyapunov Stability Analysis}

This section is related to the stability analysis of the active suspension closed loop system under the STSMC control law. The stability analysis work is done to show that the error term converges to zero in finite time. The following Lyapunov function candidate is selected for stability analysis of active quarter car model as [22]:

$£=2 k_{2}|s(t)|+\frac{1}{2}\left(k_{1}|s(t)|^{\frac{1}{2}} \operatorname{sign}(s(t))-v(t)\right)^{2}+\frac{1}{2} v(t)^{2}$ 
Equation (24) can be represented in quadratic form as follows:

$£=\Omega^{T} P \Omega$

where,

$\Omega=\left[|s(t)|^{\frac{1}{2}} \operatorname{sign}(s(t)) v(t)\right]^{T}$ and $P=\frac{1}{2}\left[\begin{array}{cc}k_{1}^{2}+4 k_{2} & -k_{1} \\ -k_{1} & 2\end{array}\right]$

Its time derivative along the solution of Eq. (24) results in the following:

$\dot{£}=-\frac{1}{|s(t)|^{\frac{1}{2}}}\left(\Omega^{T} C_{1} \Omega-d C_{2} \Omega\right)$

where,

$C_{1}=\frac{k_{1}}{2}\left[\begin{array}{cc}k_{1}^{2}+2 k_{2} & -k_{1} \\ -k_{1} & 1\end{array}\right]$ and $C_{2}=\left[\left(\frac{k_{1}^{2}}{2}+2 k_{2}\right) \quad-\frac{k_{1}}{2}\right]$

Applying the bounds on the uncertainties or perturbation in Eq. (26), as presented in [23], it can be written as:

$\dot{£} \leq-\frac{1}{|s(t)|^{\frac{1}{2}}} \Omega^{T} C_{3} \Omega$

where,

$C_{3}=\frac{k_{1}}{2}\left[\begin{array}{cc}k_{1}^{2}+2 k_{2}-\left(\frac{4 k_{2}}{k_{1}}+k_{1}\right) \delta & -k_{1}+2 \delta \\ -k_{1}+2 \delta & 1\end{array}\right]$

In present case, $\dot{£}$ is negative if $C_{3} \geq 0$, which is valid if the following conditions related to the sliding mode gains are satisfied:

$k_{1}>2 \delta$

$k_{2}>\frac{k_{1}\left(5 k_{1} \delta+4 \delta^{2}\right)}{2\left(k_{1}-2 \delta\right)}$

\section{Simulation Results and Discussion}

To study the ride comfort issues in graphical and mathematical results, simulation models for active and passive quarter car systems were designed. The random road profile used in simulation work is shown in Figure 2. The quarter car model speed was set as 40 $\mathrm{km} / \mathrm{hr}$ while the simulation was run for 4 seconds. The active and passive quarter car models performance was evaluated in vibration control of passenger seat, sprung mass and suspension systems respectively. The selected mathematical values of quarter car model for simulation work are as follows: passenger seat mass, $m_{p}=70 \mathrm{~kg}$; sprung mass, $m_{s}=325 \mathrm{~kg}$ and unsprung mass, $m_{u s}=40 \mathrm{~kg}$; the damping and stiffness parameters of main and passenger seat suspension are $\mathrm{c}_{1}=850 \mathrm{Ns} / \mathrm{m}, \mathrm{c}_{2}=$ $1550 \mathrm{Ns} / \mathrm{m}, \mathrm{k}_{1}=8500 \mathrm{~N} / \mathrm{m}, \mathrm{k}_{2}=20000 \mathrm{~N} / \mathrm{m}$ respectively. The tyre stiffness $k_{t}$ is having the value of $180,000 \mathrm{~N} / \mathrm{m}$.

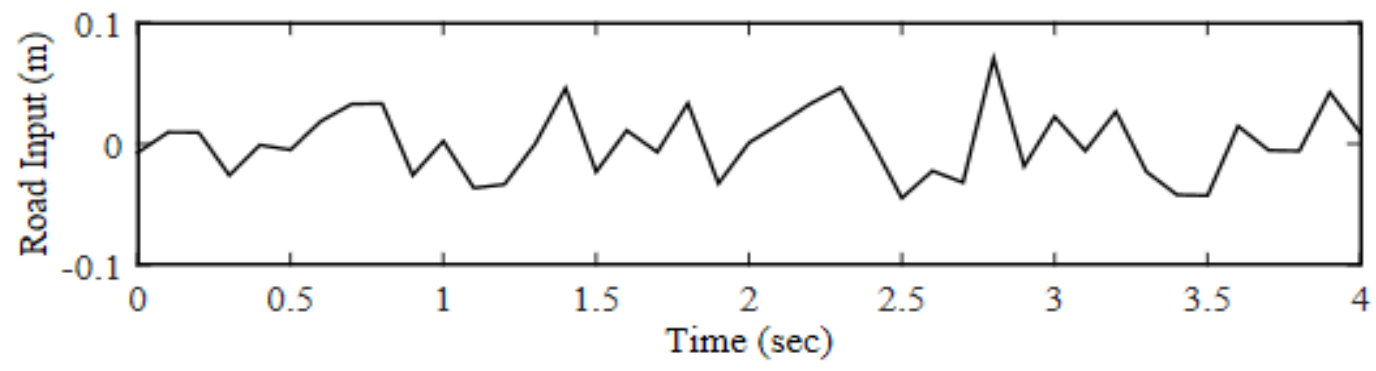

Figure 2. Random Road Profile 
The results obtained after running the simulations in time domain are presented graphically. Figure 3 - Figure 5 shows the response of passenger seat, sprung mass and suspension stroke while Figure 6 shows the damping force supplied and power consumed by STSMC controller in main suspension system respectively. It can be clearly seen from Figure 3 - Figure 4 that passenger seat and sprung mass vibrations are suppressed very much by active suspension system compared to passive one in terms of acceleration and displacement criterion. The displacement movement of passenger seat suspension and main suspension is also lower for active suspension system compared to passive one as seen in Figure 5. The graphical representation of damping force generated by STSMC controller in main suspension is given in Figure 6 (a) while the power consumed by STSMC controller for its working is shown in Figure 6 (b).

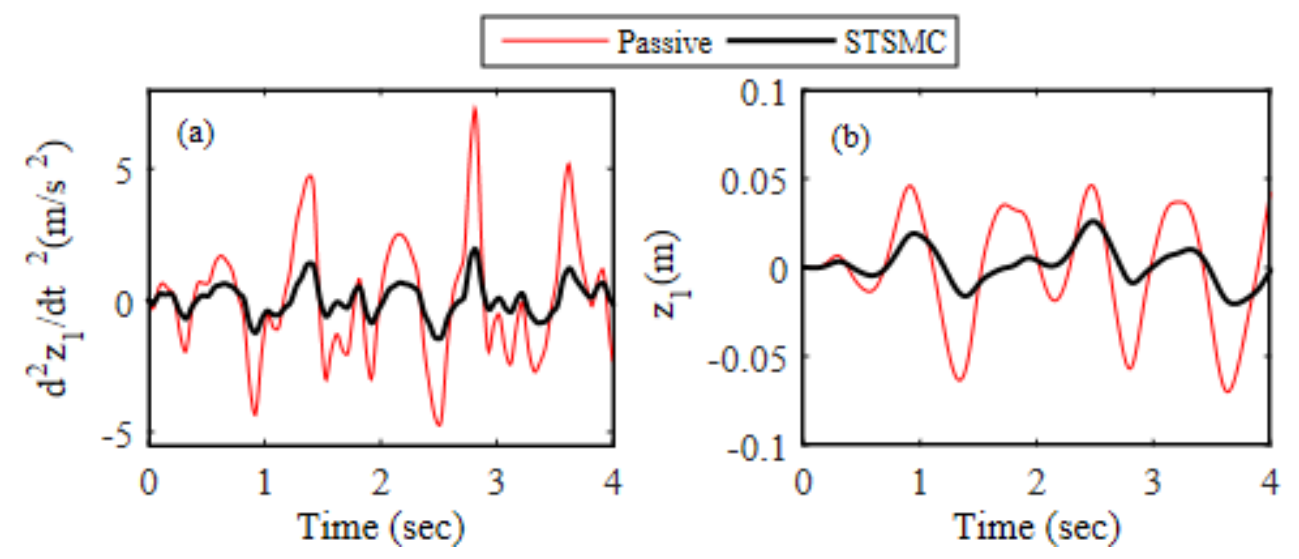

Figure 3. Passenger Seat Response (a) Acceleration (b) Displacement

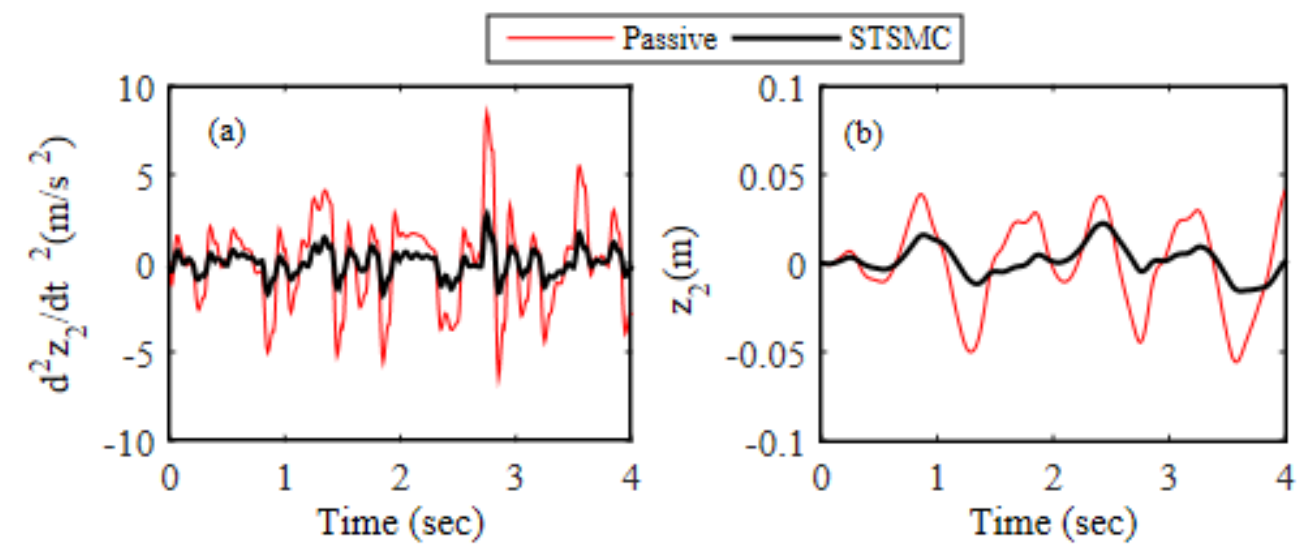

Figure 4. Sprung Mass Response (a) Acceleration (b) Displacement 


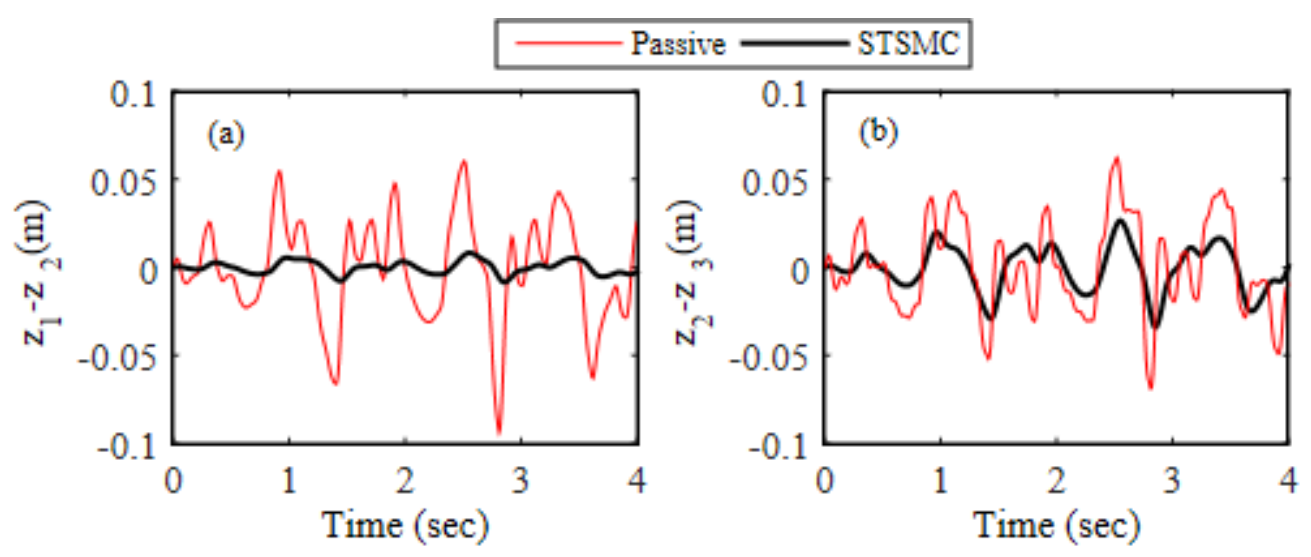

Figure 5. Suspension Stroke Response (a) Seat Suspension Displacement (b) Main Suspension Displacement
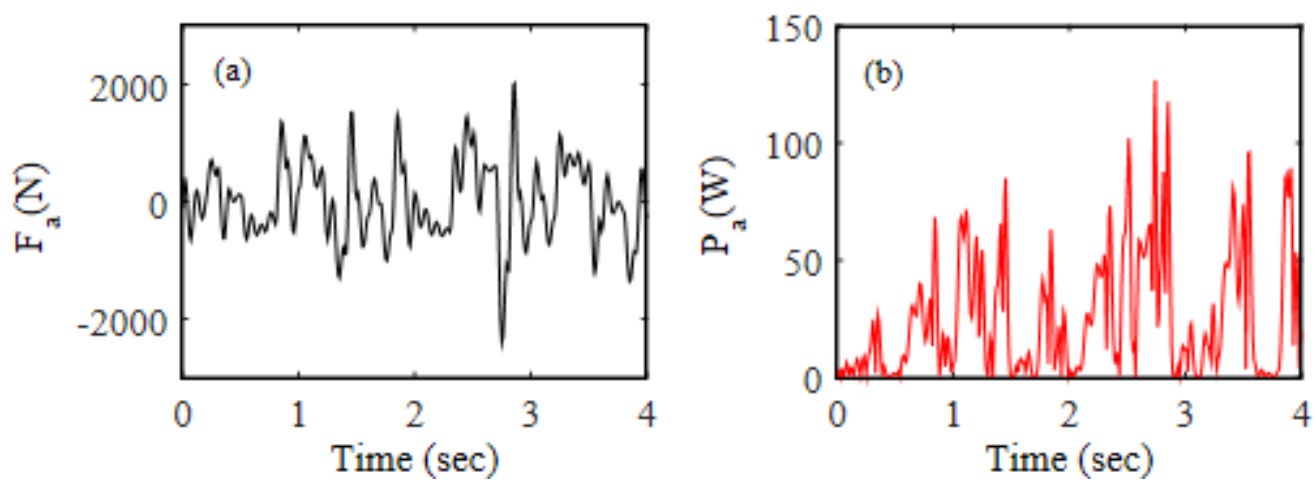

Figure 6. (a) Damping Force Supplied by STSMC Controller (b) Power Consumed by STSMC Controller

The obtained mathematical results of quarter car response from graphical response can be seen from Table 1. These simulation results clearly show the good performance delivered by STSMC controlled active suspension system in terms of peak and RMS (root mean square) values compared to passive suspension system in simulation environment.

Table 1. Simulation Results under Random Road Profile

\begin{tabular}{|c|c|c|c|c|c|}
\hline \multirow{2}{*}{$\begin{array}{l}\text { Measurement } \\
\text { point }\end{array}$} & \multirow{2}{*}{$\begin{array}{l}\text { Controller } \\
\text { Type }\end{array}$} & \multicolumn{2}{|c|}{$\begin{array}{l}\text { Acceleration } \\
\left(\mathrm{m} / \mathrm{s}^{2}\right)\end{array}$} & \multicolumn{2}{|c|}{ Displacement (m) } \\
\hline & & Peak & RMS & Peak & RMS \\
\hline \multirow{2}{*}{ Passenger seat } & Passive & 7.2780 & 2.2375 & 0.0463 & 0.0311 \\
\hline & STSMC & 1.9517 & 0.6286 & 0.0260 & 0.0105 \\
\hline \multirow{2}{*}{ Sprung mass } & Passive & 8.5057 & 2.5320 & 0.0411 & 0.0246 \\
\hline & STSMC & 2.7301 & 0.7318 & 0.0225 & 0.0089 \\
\hline
\end{tabular}

The performance of designed STSMC controller was also evaluated taking four different criterions. These criterions are integral of absolute error (IAE), integral of time multiplied absolute error (ITAE), integral of square error (ISE) and integral of time multiplied square error (ITSE) respectively. The best performance of STSMC controlled active suspension system can be seen in Table 2 on IAE, ITAE, ISE and ITSE criterion compared to passive one under random road profile. 
Table 2. Controller Response under Random Road Profile

\begin{tabular}{|c|c|c|c|c|c|}
\hline \multirow{2}{*}{$\begin{array}{l}\text { Measurement } \\
\text { point }\end{array}$} & \multirow{2}{*}{ Controller Type } & \multicolumn{4}{|c|}{ Performance } \\
\hline & & IAE & ITAE & ISE & ITSE \\
\hline \multirow{2}{*}{ Passenger seat } & Passive & 0.1344 & 0.0070 & 0.3010 & 0.0124 \\
\hline & STSMC & 0.0918 & 0.0032 & 0.2017 & 0.0056 \\
\hline \multirow{2}{*}{ Sprung mass } & Passive & 0.0992 & 0.0040 & 0.2194 & 0.0070 \\
\hline & STSMC & 0.0828 & 0.0026 & 0.1815 & 0.0046 \\
\hline
\end{tabular}

\section{PSD Analysis}

The calculated power spectral density (PSD) response of passenger seat, sprung mass and suspensions response using simulation work is seen in Figure 7-Figure 9. The PSD signals for active suspension system with STSMC controller are much suppressed in magnitude compared to passive one thus showing the superior performance of STSMC controlled active quarter car model in terms of road induced vibration control.

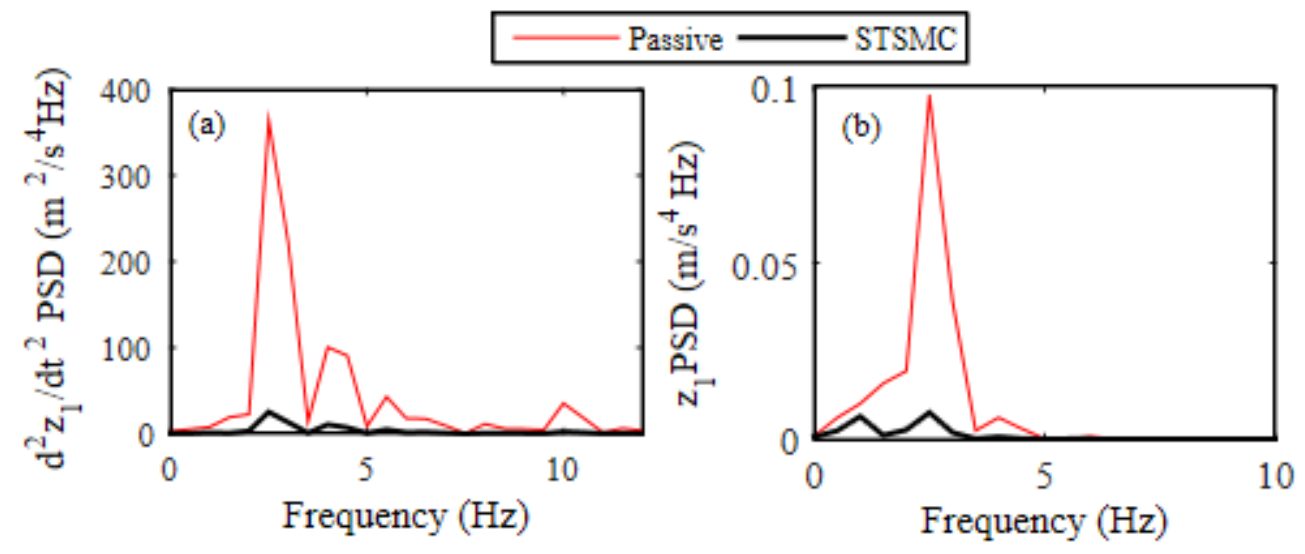

Figure 7. PSD Response of Passenger Seat (a) Acceleration (b) Displacement

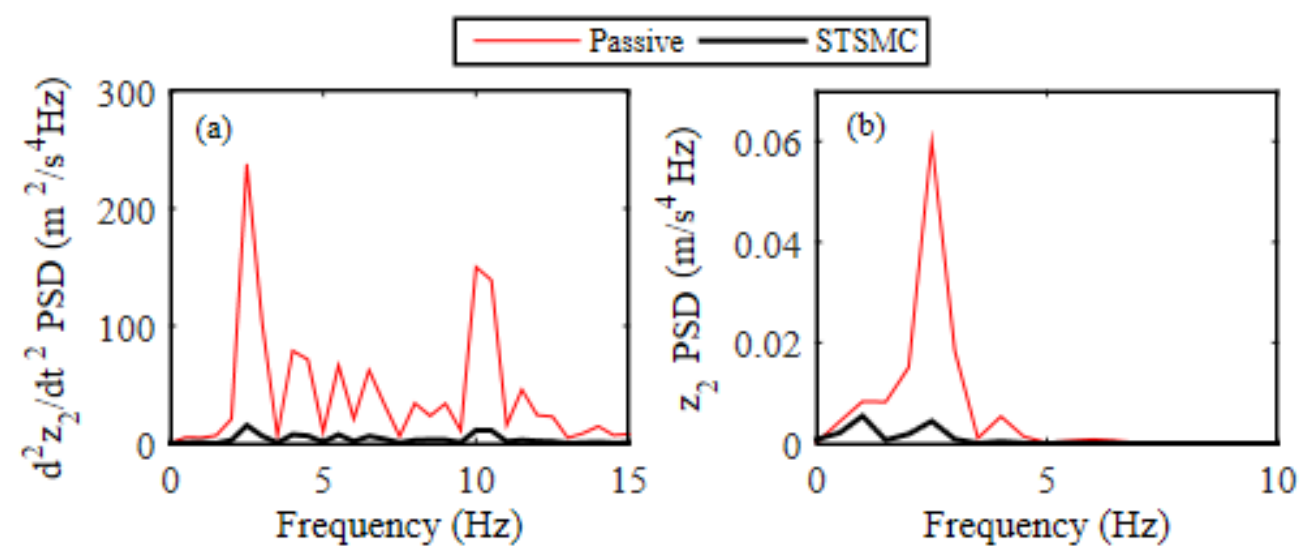

Figure 8. PSD Response of Sprung Mass (a) Acceleration (b) Displacement 


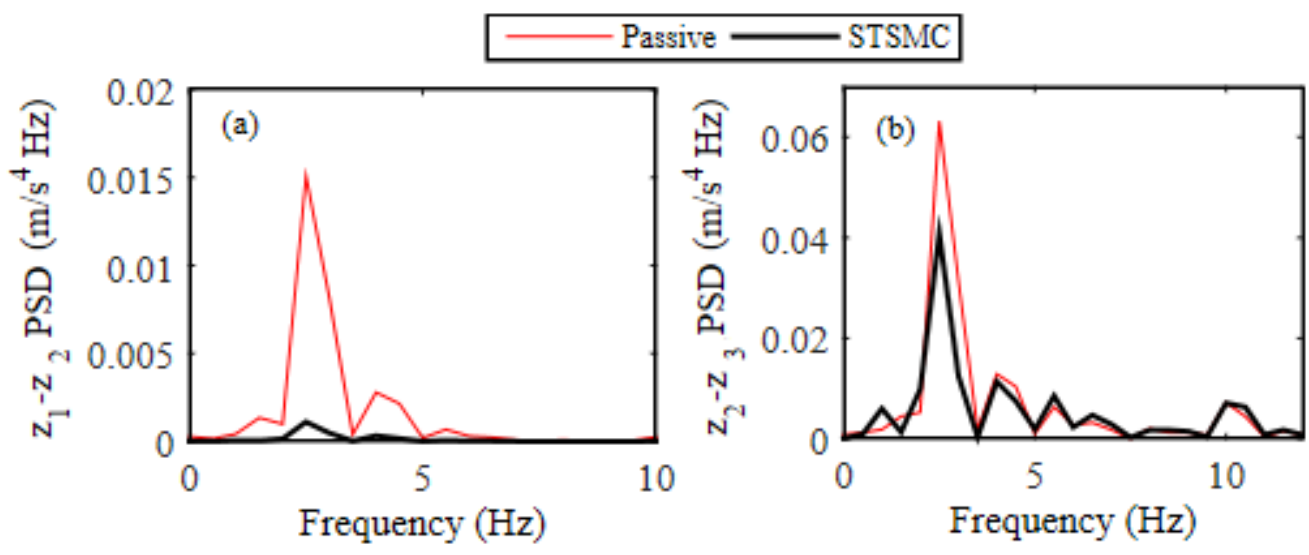

Figure 9. PSD Response of Suspension System Displacement (a) Passenger Seat Suspension (b) Main Suspension

\section{Passenger Ride Comfort Analysis}

Vibrations transmitted from road surfaces to vehicle structures also affect the body parts of travelling passengers. Such vibration exposure with high intensity and long duration can lead to health risk, injury to body parts as well as discomfort to sitting occupants in running vehicle. Hence, whole body vibration measurement is performed using ISO 2631-1 [24]. Here, the criterions selected for ride comfort evaluation are frequency Weighted RMS acceleration (WRMS) and Vibration Dose Value (VDV) respectively. The calculated values of WRMS and VDV for active and passive quarter car models are shown in Table 3. It can be observed from Table 3 that ride comfort of passengers for active suspension system is much improved compared to passive one.

Table 3. Controller Response as per ISO 2631-1

\begin{tabular}{lcc}
\hline \multirow{2}{*}{ Criterion } & \multicolumn{2}{c}{ Controller Type } \\
\cline { 2 - 3 } & Passive & STSMC \\
\hline WRMS & 1.6379 & 0.4567 \\
VDV & 9.6693 & 2.7609 \\
\hline
\end{tabular}

\section{Frequency Domain Analysis}

The calculated resonance values of the passive quarter car model with three degrees of freedom are $1.02 \mathrm{~Hz}, 2.02 \mathrm{~Hz}$ and $11.26 \mathrm{~Hz}$ respectively. These resonance values are related to passenger seat, sprung mass and unsprung mass respectively. It can be seen from Figure 10 that the passenger seat resonance peak in acceleration and displacement diagrams around $1 \mathrm{~Hz}$ is much suppressed using proposed STSMC controller compared to passive suspension system which shows passenger ride comfort is much improved. 

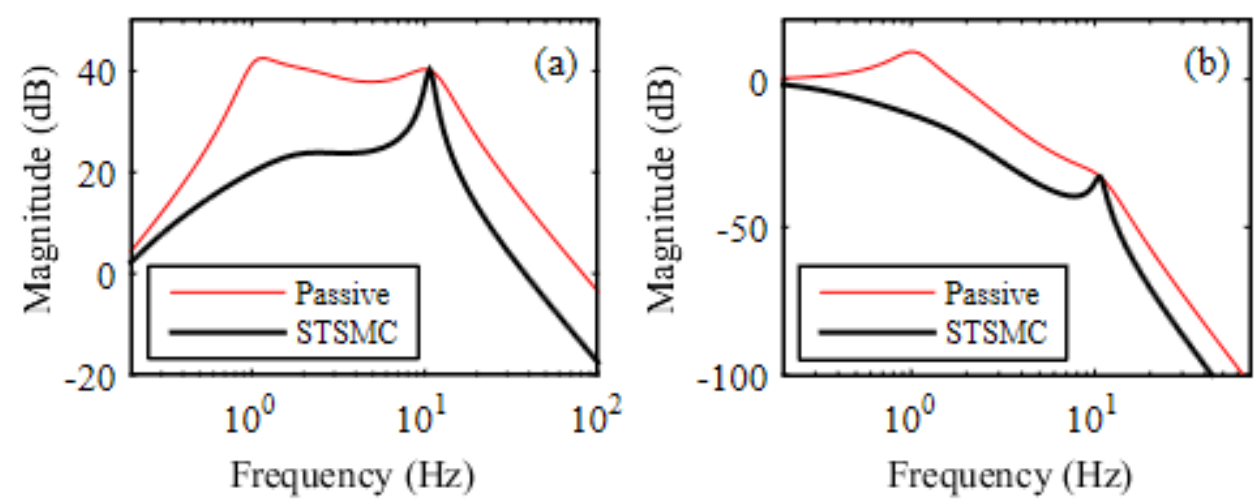

Figure 10. Frequency Response of Passenger Seat (a) Acceleration (b) Displacement

\subsection{Robustness Analysis}

In practical situations, vehicle internal parameters such as sprung mass, damper damping and spring stiffness may change depending on the working conditions. In present section, robustness of the designed STSMC controller is investigated in main suspension of the active quarter car model taking variation of selected parameters as shown in Table 4. It can be seen from Figure 11-Figure 13 that with the variation of the vehicle parameters, negligible changes related to effectiveness are observed in frequency domain for active quarter car model, showing the robustness of the proposed STSMC controller.

Table 4. Variation of Quarter Car Parameters

\begin{tabular}{cll}
\hline Parameter & \multicolumn{1}{c}{ Nominal Value } & \multicolumn{1}{c}{ Variation } \\
\hline$m_{s}$ & $325 \mathrm{~kg}$ & $\pm 40 \mathrm{~kg}$ \\
$c_{2}$ & $1550 \mathrm{~N} / \mathrm{m} / \mathrm{s}$ & $\pm 250 \mathrm{~N} / \mathrm{m} / \mathrm{s}$ \\
$k_{2}$ & $20000 \mathrm{~N} / \mathrm{m}$ & $\pm 3500 \mathrm{~N} / \mathrm{m}$ \\
\hline
\end{tabular}
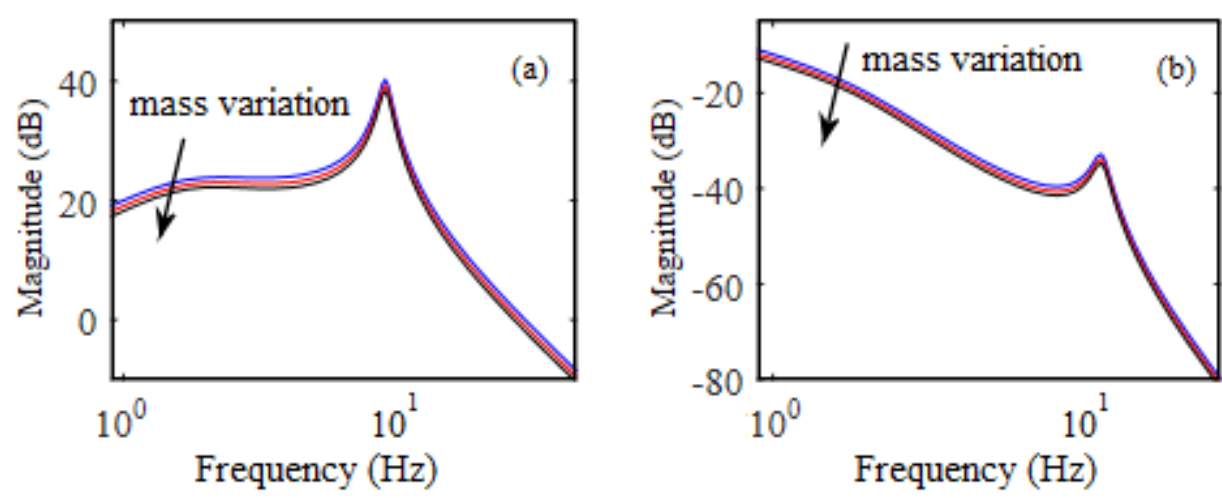

Figure 11. Bode Plot for Sprung Mass Variation (a) Passenger Seat Acceleration (b) Passenger seat Displacement 

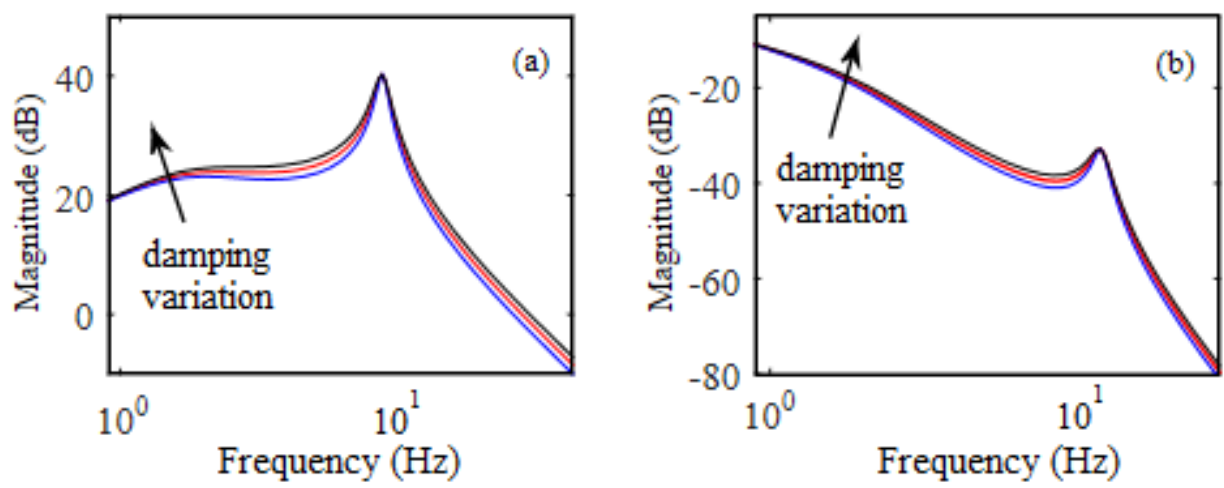

Figure 12. Bode Plot for Damping Variation (a) Passenger Seat Acceleration (b) Passenger Seat Displacement
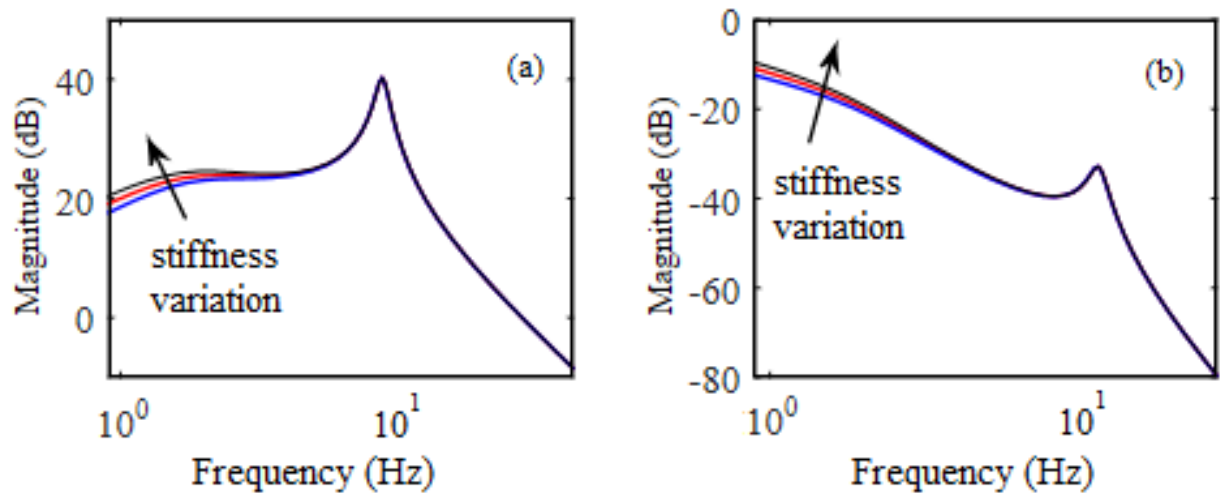

\section{Figure 13. Bode Plot for Spring Stiffness Variation (a) Passenger Seat Acceleration (b) Passenger Seat Displacement}

\section{Conclusions}

This paper presented the successful application of SMSTC controller in active suspension system of quarter car model in vibration control of passenger seat, sprung mass and suspension system under random road excitation. Simulation results in time and frequency domain showed the effectiveness of proposed STSMC controller in providing high ride comfort to travelling passengers compared to passive one. The proposed controller also showed the robust behaviour when magnitudes of three parameters namely sprung mass, damper damping and spring stiffness were varied.

\section{References}

[1] H. Metered, "Application of nonparametric magnerorheological damper model in vehicle semi-active suspension system", SAE International Journal of Passenger Cars, Mechanical Systems, vol. 5, (2012), pp. 715-726.

[2] Devdutt and M. L. Aggarwal, "Fuzzy control of passenger ride performance using MR shock absorber suspension in quarter car model", International Journal of Dynamics and Control, vol. 3, no. 4, (2015), pp. 463-469.

[3] Devdutt and M. L. Aggarwal, "Passenger seat vibration control of a semi-active quarter car system with hybrid Fuzzy - PID approach”, International Journal of Dynamics and Control, vol. 5, no. 2, (2017), pp. 287-296.

[4] D. Fischer and R. Isermann, "Mechatronic semi-active and active vehicle suspensions", Control Engineering Practice, vol. 12, (2004), pp. 1353-1367.

[5] D. Hrovat, "Survey of advanced suspension developments and related optimal control applications", Automatica, vol. 33, no. 10, (1997), pp. 1781-817.

[6] J. Cao, P. Li and H. Liu, "An interval fuzzy controller for vehicle active suspension systems", IEEE Trans. on Intelligent Transportation Systems, vol. 11, (2010), pp. 885-895. 
[7] M. Heidari and H. Homaei, "Design a PID Controller for Suspension System by Back Propagation Neural Network", Hindawi Publishing Corporation Journal of Engineering, vol 2013, Article ID 421543, p. 9.

[8] Devdutt, "Self-Tuning Fuzzy Control of Seat Vibrations of Active Quarter Car Model”, World Academy of Science, Engineering and Technology, vol. 11, no. 5, (2017), pp. 1053-1059.

[9] W. Sun, H. Gao and O. Kaynak, "Finite frequency $\mathrm{H} \infty$ control for vehicle active suspension systems", IEEE Trans. Control System Technology, vol. 19, (2011), pp. 416-22.

[10] J. Luczko and U. Ferdek, "Continuous And Discrete Sliding Mode Control Of An Active Car Suspension System", Journal of Theoretical And Applied Mechanics, vol. 54, no. 1, (2016), pp. 3-11.

[11] M. Nagarkar, G. Vikhe, K. Borole and V. Nandedkar, "Active control of quarter-car suspension system using linear quadratic regulator", International Journal of Automotive and Mechanical Engineering, vol. 3, (2011), pp. 364-372.

[12] L. Chai, T. Sun and J. Feng, "Design of the LQG controller for active suspension system based on analytic hierarchy process", Automotive Engineering, vol. 32, no. 8, (2010), pp. 712-718.

[13] S. Park and S. Rahmdel, "A new fuzzy sliding mode controller with auto-adjustable saturation boundary layers implemented on vehicle suspension", International Journal of Engineering- Transactions C: Aspects, vol. 26, no. 12, (2013), pp. 1401-1410.

[14] Q. Yun, Y. Zhao and H. Yang, "A dynamic sliding-mode controller with fuzzy adaptive tuning for an active suspension system”, Proc. IMechE Part D: Journal of Automobile Engineering, vol. 221, (2007), pp. 417-428.

[15] I. Fialho and G. J. Balas, "Road adaptive active suspension design using linear parameter-varying gainscheduling", IEEE Transactions on Control System Technology, vol. 10 , no. 1, (2002), pp. 43-54.

[16] R. Kalaivani, K. Sudhagar and P. Lakshmi, "Neural Network based Vibration Control for Vehicle Active Suspension System", Indian Journal of Science and Technology, DOI: 10.17485/ijst/2016/v9i1/83806, vol. 9, no. 1, (2016).

[17] R. Kothandaraman and L. Ponnusamy, "PSO tuned Adaptive Neuro-fuzzy Controller for Vehicle Suspension Systems", Journal of Advances in Information Technology, vol. 3, no. 1, (2012), pp. 57-63.

[18] H. M. Fard and F. Samadi, "Active Suspension System Control Using Adaptive Neuro Fuzzy (ANFIS) Controller”, IJE TRANSACTIONS C: Aspects, vol. 28, no. 3, (2015), pp. 396-401.

[19] Devdutt and M. L. Aggarwal, "Active vibration control of passenger seat with HFPIDCR controlled suspension alternatives", International Journal of Mechanical, Aerospace, Industrial, Mechatronics and Manufacturing Engineering, vol. 10, no. 5, (2016), pp. 916-923.

[20] O. Demir, I. Keskin and S. Cetin, "Modeling and control of nonlinear half-vehicle suspension system: a hybrid fuzzy logic approach", Nonlinear Dyn, vol. 67, (2012), pp. 2139-2151.

[21] A. Levant, "Sliding order and sliding accuracy in sliding mode control", International Journal of Control, vol. 58, no. 6, (1993), pp. 1247-1263.

[22] J. A. Moreno and M. Osorio, "A Lyapunov approach to second-order sliding mode controllers and observers", 47 $7^{\text {th }}$ IEEE Conference on Decision and Control, (2008), pp. 2856-2861.

[23] J. S. Thongam, P. Bouchard, H. Ezzaidi and M. Ouhrouche, "Wind speed sensorless maximum power point tracking control of variable speed wind energy conversion systems", IEEE International Electric Machines and Drives Conference, Miami, USA, (2009), pp. 2195-2200.

[24] ISO: 2631-1, Mechanical vibration and shock - evaluation of human exposure to whole - body vibration; (1997).

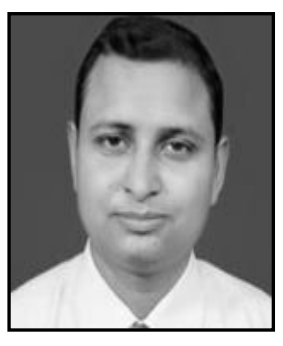

Devdutt Singh, he completed $\mathrm{Ph} \mathrm{D}$ from YMCA University of Science and Technology, Faridabad in 2016. Presently he is working as Associate Professor in the Department of Mechanical Engineering, Faculty of Engineering and Technology, Manav Rachna International University, Faridabad. He is having 9 years of teaching and 4 years of industrial experience. His research areas of interest are noise, vibration and ride quality related to semi-active and active vehicle suspension system. 